V Congresso Brasileiro de Informática na Educação (CBIE 2016)

Anais dos Workshops do V Congresso Brasileiro de Informática na Educação (CBIE 2016)

\title{
Plataforma CultivEduca
}

\section{Marie Jane Carvalho' ${ }^{1}$, Breno Neves ${ }^{2}$, Rafaela Melo ${ }^{3}$}

${ }^{1}$ Programa de Pós-Graduação em Informática na Educação - Universidade Federal do Rio Grande do Sul (UFRGS) - Porto Alegre - RS - Brasil

2Programa de Pós-Graduação em Educação - Universidade Federal do Rio Grande do Sul (UFRGS) - Porto Alegre - RS - Brasil.

3Programa de Pós-Graduação em Educação - Universidade Federal do Rio Grande do Sul (UFRGS) - Porto Alegre - RS - Brasil

marie.jane@ufrgs.br, breno@brenoneves.org, rafaela@rafaelamelo.org

Resumo. Aplicação derivada de dados educacionais abertos disponíveis pelo Instituto Nacional de Pesquisas Educacionais Anísio Teixeira (INEP) que permite conhecer o perfil de formação dos profissionais do magistério da educação básica, das redes públicas e privada, de todas as escolas do Brasil. A Plataforma agrega as informações para a federação, as unidades da federação, os municípios, as escolas $e$ as turmas. Os dados de formação inicial e continuada dos professores são distribuídos por ano, desde 2009 e atualizados anualmente por redes de ensino e por etapas da educação básica. O objetivo é atender ao planejamento de gestores educacionais e a análise de pesquisadores.

\section{Cenário de uso}

A maior parte dos componentes curriculares (disciplinas), nas escolas do Brasil, é atendido por professores sem licenciatura e com formação inicial em áreas diferentes das que atuam nas salas de aula. A maior parte dos professores, no país, não tem formação continuada adequada nem formação de pós-graduação. Este cenário e a perspectiva de mudança estão contemplados nas Metas 15, 16, 17 e 18 do Plano Nacional de Educação/PNE (Todos pela Educação, 2014), para o decênio 2014/2014, que se propõem a:

- Assegurar que todos os profissionais do magistério da educação básica possuam formação específica de nível superior, obtida em curso de licenciatura na área de conhecimento em que atuam.

- Formar, em nível de pós-graduação, 50\% dos profissionais do magistério da educação básica, até o último ano de vigência deste PNE, e garantir a todos os profissionais da educação básica formação continuada em sua área de atuação. 
V Congresso Brasileiro de Informática na Educação (CBIE 2016)

Anais dos Workshops do V Congresso Brasileiro de Informática na Educação (CBIE 2016)

- Valorizar os profissionais do magistério das redes públicas de educação básica de forma a equiparar seu rendimento médio ao dos demais profissionais com escolaridade equivalente.

- Assegurar, no prazo de dois anos, a existência de planos de carreira para os profissionais da educação básica e superior pública de todos os sistemas de ensino.

A formação acadêmica dos profissionais do magistério é um direito, é uma condição essencial e um requisito indispensável ao exercício profissional docente. A formação dos profissionais do magistério é considerada estratégica para a melhoria da educação no país. Entretanto, os gestores educacionais, as instituições de ensino e os governos locais encontram dificuldades em levantar informações precisas sobre a formação inicial e ou continuada dos profissionais do magistério. Quem são e onde estão os que precisam de formação? Quais cursos de formação inicial ou continuada devem ser privilegiados, considerando os recursos disponíveis? Essas são questões que necessitam respostas claras com vistas ao bom planejamento educacional.

Na perspectiva de atender a carência de informação, sobre os profissionais do magistério, é que criamos a Plataforma CultivEduca (M. J. Carvalho, B. Neves, \& R. Melo, 2015). Esta plataforma agrega dados do censo escolar (Instituto Nacional de Estudos e Pesquisas Educacionais, 2015) e os organiza de modo a permitir que os gestores, os pesquisadores e a comunidade em geral possam localizar, rápido e facilmente, os dados sociodemográficos e as informações sobre a formação inicial e continuada de todos os profissionais do magistério da educação básica do Brasil. As informações sociodemográficas compreendem: sexo, cor/raça, zona de atuação, idade, professores com deficiência, tipo de contrato. A Plataforma apresenta, detalhadamente, os dados sobre a adequação entre a formação e a atuação do profissional ao especificar em qual disciplina o professor atua e qual é a sua formação inicial. Ao separar estas informações, a Plataforma informa o número de professores que se encontra para cada disciplina, conforme sua formação.

A Plataforma é de fácil compreensão ao exigir conhecimento mínimo e capacidade de leitura de tabelas, gráficos e dados. Ela se endereça aos gestores educacionais e aos pesquisadores, mas está amplamente disponível para qualquer pessoa que se interesse em saber como é a formação dos professores que atendem a escola tal ou a turma do seu filho, por exemplo.

A Plataforma CultivEduca é trabalhada nas áreas de políticas públicas da educação e de formação de professores nos cursos de licenciatura. Todavia, é importante registrar que a plataforma nasceu de uma demanda do Fórum Estadual Permanente de Apoio à Formação Docente do Rio Grande do Sul (FEPAD/RS). 
V Congresso Brasileiro de Informática na Educação (CBIE 2016)

Anais dos Workshops do V Congresso Brasileiro de Informática na Educação (CBIE 2016)

Os FEPADs, no Brasil, respondem pelo planejamento estratégico de formação inicial e continuada dos profissionais da educação, em geral, e do magistério, em particular.

Esta Plataforma faz parte do diagnóstico da condição de formação dos professores, exigido pela legislação educacional no Brasil. Em especial, interessanos a Lei no. 13.005/2014 que aprovou o Plano Nacional de Educação, o Decreto 8.752/2016 (que substituiu o Decreto 6.755/2009) que dispõe sobre a Política Nacional de Formação dos Profissionais da Educação Básica e a Resolução no. 2/2015 do Conselho Nacional de Educação que apresenta as Diretrizes Curriculares Nacionais para a Formação Inicial e Continuada dos Profissionais do Magistério da Educação Básica. A Plataforma é um instrumento para a realização de diagnósticos com vistas ao planejamento estratégico nos Fóruns Estaduais e nas Secretarias de Educação das redes de ensino pública.

\section{Desenvolvimento}

Os estudos para o desenvolvimento da Plataforma de visualização de dados educacionais CultivEduca iniciaram em 2013, diante da necessidade de localização correta das demandas por formação inicial e continuada entre os profissionais do magistério da educação básica do Brasil. O desenvolvimento da Plataforma, em 2014, foi realizado em três módulos: leitura dos microdados; criação dos perfis e desenvolvimento da interface web.

O primeiro módulo, responsável pela leitura dos arquivos de microdados do Educacenso, disponibilizados pelo INEP anualmente, possui as funções necessárias para preparar os dados de 2009 a 2015 de forma estruturada, normalizando o nome e o significado das variáveis, considerando que estas se alteram ao longo do tempo.

O segundo módulo organiza as respostas do Educacenso em grupos de docentes, os quais denominamos simplesmente "perfis". O CultivEduca considera como perfil cada estado, cada município, cada escola e cada turma, agrupando todos os docentes por perfis. Os perfis internamente podem ter filtros específicos, como a etapa de ensino e dependência administrativa.

Após o agrupamento dos docentes, são contabilizados dados demográficos (número de docentes, idade, sexo, zona e professores com deficiências), dados sobre a formação inicial (fundamental incompleto, fundamental completo, ensino médio, normal, superior incompleto/em andamento e superior completo), formação continuada (pós graduação: especialização, mestrado, doutorado e cursos de formação continuada com carga horária de, no mínimo, 80 horas) e dados sobre a atuação do docente (disciplinas em que atua). 
V Congresso Brasileiro de Informática na Educação (CBIE 2016)

Anais dos Workshops do V Congresso Brasileiro de Informática na Educação (CBIE 2016)

Os dados são consolidados em um banco de dados MySQL, tendo como chave primária o ano, o número do perfil e a variação do perfil (filtro), armazenando os dados em uma tabela independente para cada informação: profile_name (nome do grupo/perfil), data_idade (idade), data_main_stats (número, sexo e zona:urbana/ rural), data_formini (formação inicial), data_formcont (formação continuada), data_adequacao (adequação disciplina/formação), data_pcd (pessoas com deficiência). Há duas tabelas que armazenam apenas dados estruturais: ano, que indica a existência dos perfis em determinado ano e a tabela profile_parent, que indica a relação hierárquica entre os perfis (Brasil $>$ Estado $>$ Município $>$ Escola $>$ Turma).

O terceiro módulo consiste em uma interface Web, acessível pela Internet em http://cultiveduca.ufrgs.br/. Este módulo foi instalado em um servidor Web que apenas realiza o acesso ao banco de dados e gera páginas HTML que permitem a navegação entre os diversos perfis e a visualização dos dados de forma gráfica utilizando o framework Google Charts.

No decorrer do desenvolvimento da plataforma foram utilizadas apenas tecnologias sob licenças livres. A linguagem de programação escolhida para o desenvolvimento da Plataforma é Python2, o banco de dados MySQL e a interface Web foi desenvolvida em HTML5, com uso do framework WebPy.

\section{Apresentação da Plataforma CultivEduca - Valorizar do Educador faz toda a diferença}

A página inicial (Figura 1) é composta por dois menus (dados e legislação sobre a formação docente), um campo de busca (para a localização do perfil dos docentes por estado, município, escola de qualquer região do Brasil), apresentação geral das informações que podem ser localizadas (créditos e referências adicionais).

Figura 1 - Página inicial do CultivEduca

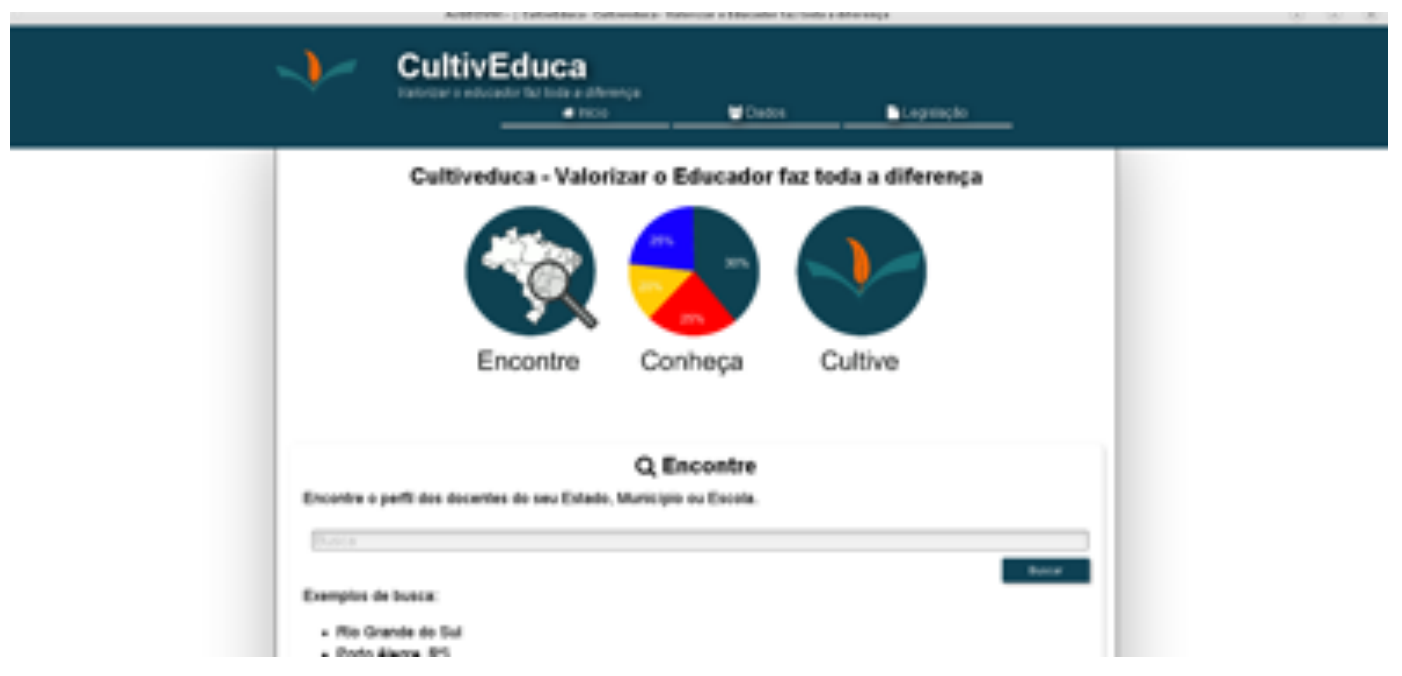


V Congresso Brasileiro de Informática na Educação (CBIE 2016)

Anais dos Workshops do V Congresso Brasileiro de Informática na Educação (CBIE 2016)

É possível visualizar os dados selecionando o menu "Dados" (Figura 2), que apresenta três opções: visualização de dados do perfil da formação docente em nível nacional, a metodologia do tratamento da base de dados utilizada na Plataforma e um campo de busca, semelhante ao encontrado na página inicial, que permite a localização do perfil docente por estado, município ou escola.

Figura 2 - Página do menu localização dos dados

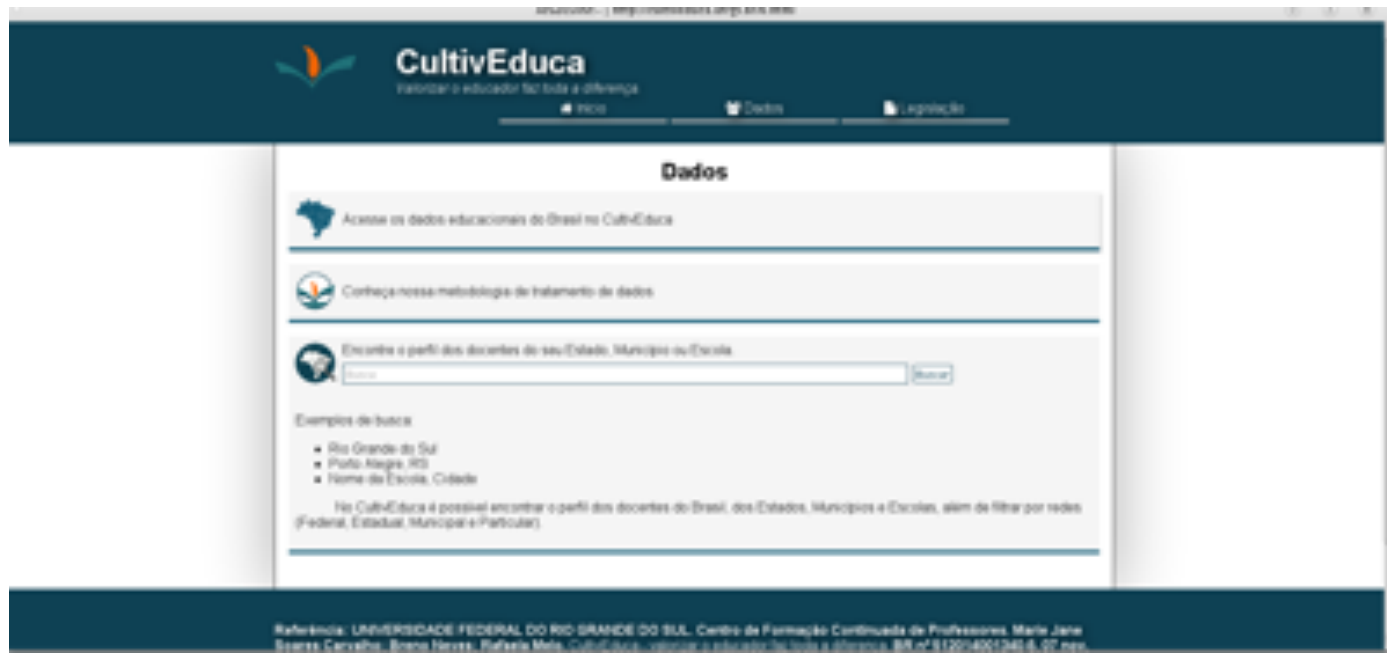

Após a inserção no campo de busca do estado, município ou escola, o visitante é redirecionado para uma página onde os dados estão disponíveis para consulta. No exemplo abaixo (Figura 3), os dados apresentados mostram o perfil da formação docente em nível nacional.

Figura 3 - Dados sobre o total de docentes e média de turmas por docente - Brasil 2015

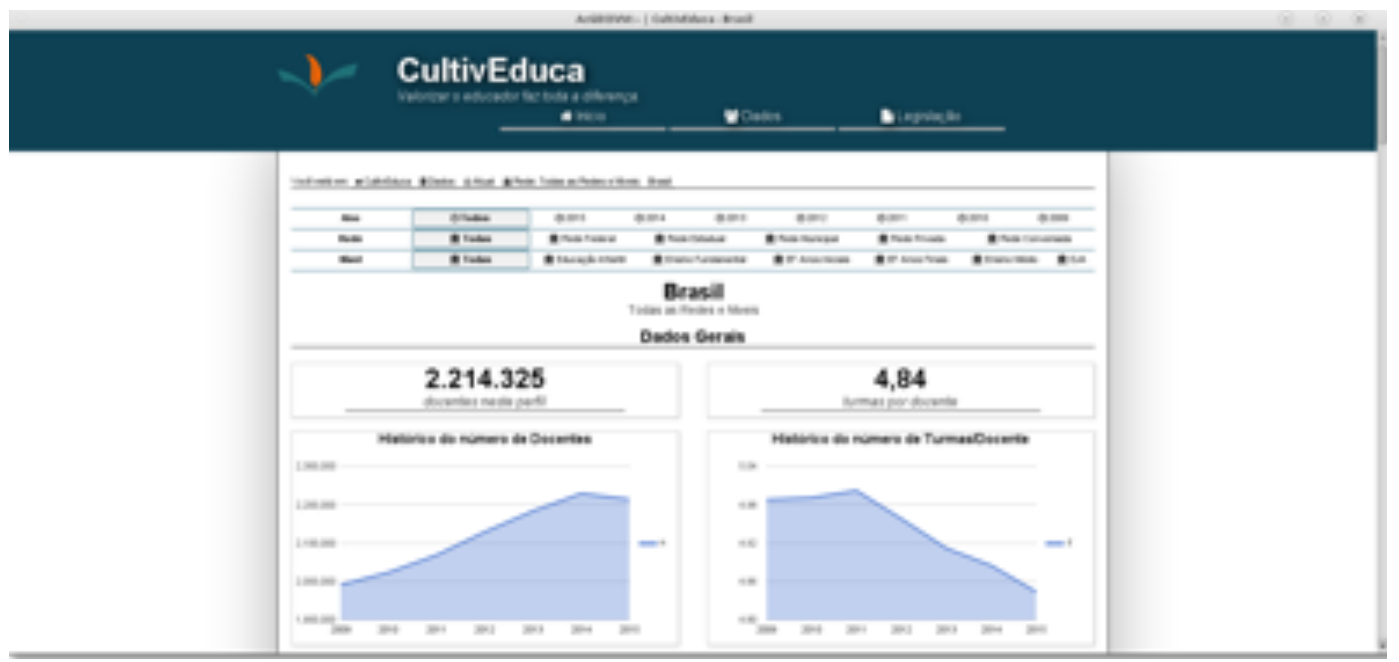


V Congresso Brasileiro de Informática na Educação (CBIE 2016)

Anais dos Workshops do V Congresso Brasileiro de Informática na Educação (CBIE 2016)

Deste ponto em diante, o visitante pode simplesmente rolar a barra lateral para ver todas as informações sobre os docentes no Brasil. (Figura 3.1)

Figura 3.1 - Dados de formação inicial, pós-graduação e formação continuada para os docentes - Brasil 2015

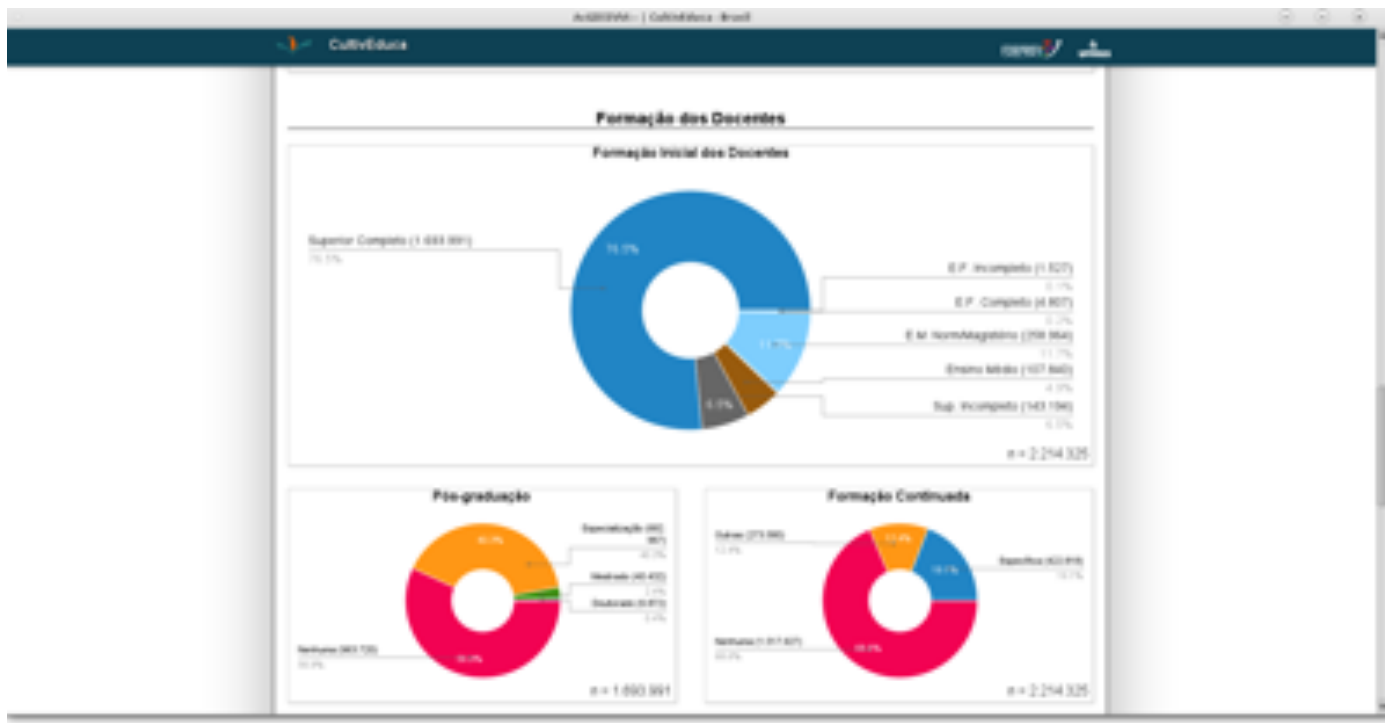

Em continuidade, pode-se buscar um estado específico no menu inferior. Ao entrar no estado busca-se qualquer município e, neste, qualquer escola e na escola se localizam todas as turmas. Para buscar o ano, a rede e a etapa de ensino, clique no menu superior. Observe o exemplo apresentado na Figura 4.

Figura 4 - Professores da rede estadual e do ensino fundamental - Porto Alegre 2014 (selecionados no menu superior)

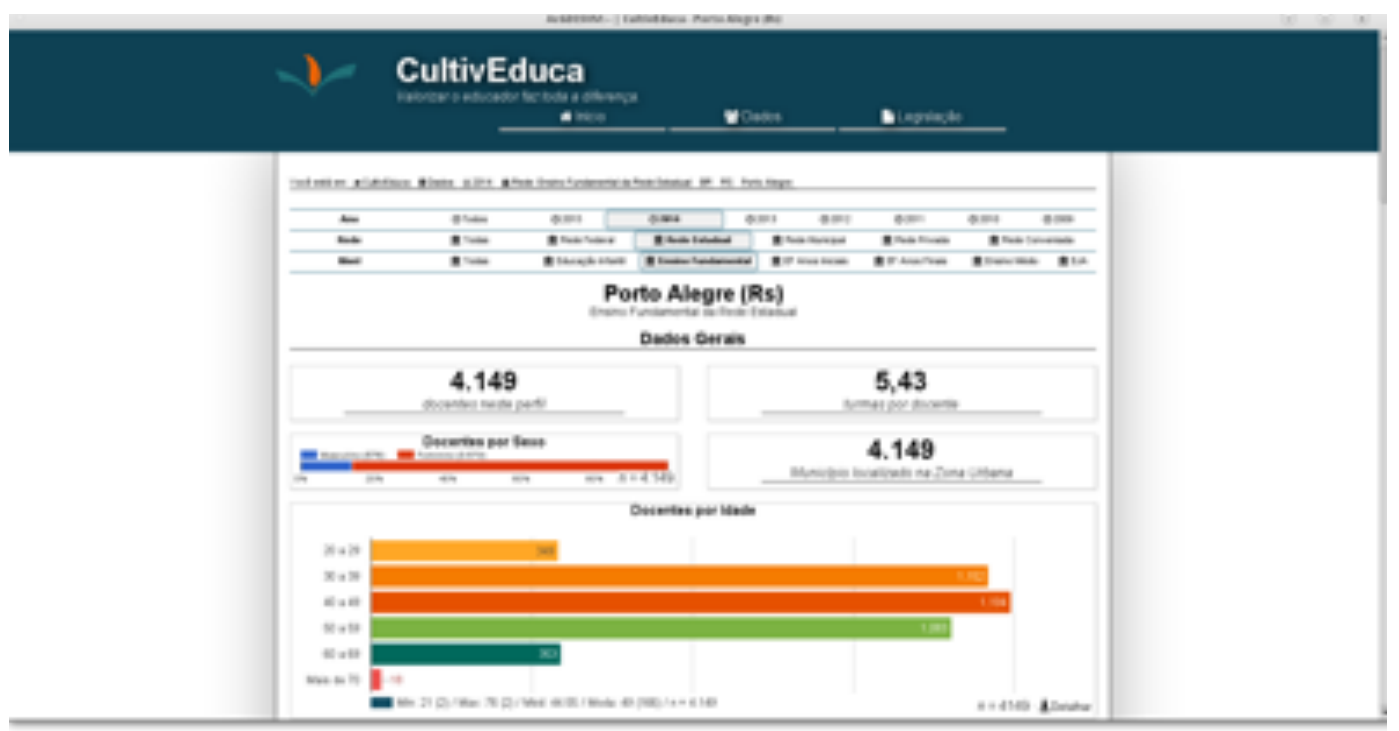


V Congresso Brasileiro de Informática na Educação (CBIE 2016)

Anais dos Workshops do V Congresso Brasileiro de Informática na Educação (CBIE 2016)

É possível fazer inúmeras combinações de dados usando o menu superior e buscar a localização no menu inferior para estados, municípios, escolas e turmas ao rolar a barra lateral até o menu inferior da tela (Figura 5).

Figura 5 - Exemplo - menu inferior e as escolas em Porto Alegre

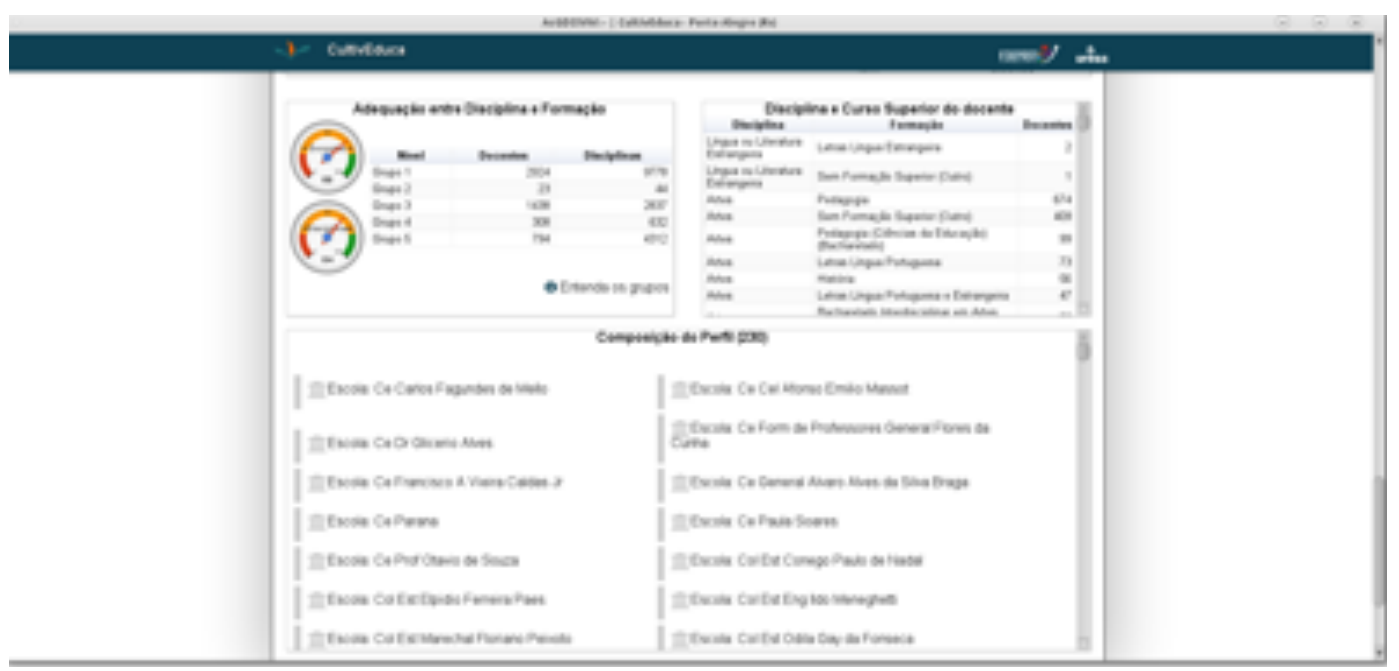

O mesmo tipo de informação e seu ordenamento visualizados para a federação são empregados para todas as seleções - as unidades da federação, os municípios, as escolas e as turmas, o que facilita a compreensão do leitor.

\section{Considerações finais}

A plataforma CultivEduca se destina a contribuir com informações, extraídas anualmente do censo escolar da educação básica, sobre o estado e a condição de formação inicial e continuada dos profissionais do magistério.

O principal resultado é a utilização da plataforma CultivEduca para o planejamento estratégico da formação docente nos estados, nos municípios e nas instituições de ensino básico e superior. Os dados sobre adequação entre a disciplina no currículo, a formação inicial necessária e a disciplina na qual o professor atua são altamente relevantes para o planejamento estratégico. Estas informações têm maior relevância quando analisadas em conjunto com os dados sociodemográficos, apresentados no CultivEduca.

À medida que a plataforma CultivEduca se torna mais conhecida, maior é a demanda de gestores e pesquisadores para a incorporação de novos dados agregados, como é o caso da última variável disponível, neste ano (2016), que informa o tipo de contratação do docente. Sabe-se imediatamente o número e o percentual correspondente de professores nas escolas com contrato temporário, o que configura uma situação de precarização do trabalho docente. 
V Congresso Brasileiro de Informática na Educação (CBIE 2016)

Anais dos Workshops do V Congresso Brasileiro de Informática na Educação (CBIE 2016)

A plataforma CultivEduca recebeu registro de programa de computador pelo Instituto Nacional da Propriedade Intelectual em 2015 (M. J. S. Carvalho, B. G. B. Neves, \& R. d. S. Melo, 2015).

Nosso projeto futuro é tornar a visualização de dados cada vez mais amigável e incorporar ferramentas novas de agregação de dados, facilmente manipuláveis pelos interessados.

\section{References}

Carvalho, M. J., Neves, B., \& Melo, R. (2015). Brasil Patent No. BR 512014 001340-5. Revista da Propriedade Industrial, No. 2346 de 22 de dezembro de 2015, p. 288: Instituto Nacional da Propriedade Intelectual \& I. o. e. G. f. e. R. DICIG - Diretoria de Contratos.

Carvalho, M. J. S., Neves, B. G. B., \& Melo, R. d. S. (2015). CultivEduca: valorizar o educador faz toda a diferença (Version 3a.) [Registro de Programa de Computador]. Brasil. Dados agregados - formação dos professores da Educação Básica. Retrieved from http://cultiveduca.ufrgs.br/

Instituto Nacional de Estudos e Pesquisas Educacionais. (2015). Educacenso. Retrieved from http://portal.inep.gov.br/web/educacenso

Todos pela Educação. (2014). Observatório do PNE. Retrieved from http:// www.observatoriodopne.org.br/sobre-observatorio 